\title{
Analysis and Impact Evaluation of Entrepreneurs' Improvisational Behavior Trigger Patterns
}

\author{
Ying Liu, Sheng-Yuan Wang $\mathbb{D}^{D}$, Xiao-Lan Wu, and Jing Liang
}

Nanjing Xiaozhuang University, Nanjing, Jiangsu, China

Correspondence should be addressed to Sheng-Yuan Wang; 56439976@qq.com

Received 13 November 2021; Accepted 27 December 2021; Published 10 January 2022

Academic Editor: Chiara Bedon

Copyright (c) 2022 Ying Liu et al. This is an open access article distributed under the Creative Commons Attribution License, which permits unrestricted use, distribution, and reproduction in any medium, provided the original work is properly cited.

\begin{abstract}
How entrepreneurial firms can enhance the level of exploratory and exploitative improvisation in a balanced manner to enhance organizational dynamics has become an important research topic. Current research on the triggers of duality entrepreneurial improvisation has just started, exploring mainly abstract characteristic variables, and has not paid attention to the impact of entrepreneurs' daily behaviors. In order to make up for the shortcomings of current research, the research goal of this paper is to construct a triggering model of entrepreneurs' improvisation based on the research of entrepreneurs' daily behaviors and then to evaluate the influence of the improvisational behavior trigger patterns. Based on the paradoxical and theoretical perspective of duality, a structured observation method is used to explore which behavioral patterns of entrepreneurs tend to trigger dual improvisational behaviors in themselves, their teams, and their organizations. After observing and recording the creators and collecting phenomenal data, six entrepreneurial behavior patterns containing 39 specific operational behaviors have been extracted from the phenomenal data by drawing on the rooted theory approach. In addition, the influence of entrepreneurial patterns is evaluated and ranked using the pairwise hesitant fuzzy set evaluation method. This study reveals the relationship between entrepreneurs' daily behaviors and dyadic entrepreneurial improvisation at the operational level and provides guiding plans for entrepreneurs to improve their own and their organizations' improvisation levels.
\end{abstract}

\section{Introduction}

Entrepreneurial improvisation refers to a highly integrated pattern of behavior in which entrepreneurs and entrepreneurial teams rapidly reconfigure, integrate, and utilize resources at hand in response to the complex and changing environments, spontaneous and creative handling of unexpected events, and continuous change to maintain business competitiveness. Several studies have shown that for highly responsive organizations, entrepreneurial improvisation largely predicts the performance gap between them $[1,2]$.

Scholars have also found that the action logic of entrepreneurial improvisation should follow the law of duality and quickly searching for new resources and ideas; the latter aims at sustaining the process and condensing existing resources on the spot to provide solutions; over-intensifying one behavior may result in negative performance impacts $[3,4]$. For example, in today's highly dynamic competitive environment, where the key criterion for business superiority is sometimes a technological breakthrough and sometimes becomes a swift consumer response, neither conservative improvisational development nor radical improvisational exploration can ensure sustainable competitiveness of a company, and both need to be weighted to change at the right time. In contrast, Ambidexterity Theory suggests that exploration and development behaviors compete for resources and are self-reinforcing, but a balanced increase in the level of both may stimulate interactive gain effects [5]. Based on the above view, recent empirical studies have also found that dual entrepreneurial improvisation can improve firms' dual learning ability and dual entrepreneurial performance under certain conditions [6]. With regard to duality, as stated by scholars such as Boumgarden [7], exploration and exploitative behaviors show complementary patterns in entrepreneurial activities, enabling routine and creative activities to go hand in hand. 
However, research on dual entrepreneurial improvisation has just begun and has only explored the dual connotations and positive utility of the entrepreneurial team level, while it is unclear how it occurs in teams, and no research has explored the entrepreneurial behavioral underpinnings that induce its occurrence. At a broader level, on the one hand, most studies on the antecedents of organizational improvisation have focused on environmental or organizational contextual factors outside of the improvisation unit, such as environmental dynamics, experimental culture, and inclusive leadership, with insufficient research on the intrinsic triggering mechanisms, which are mostly abstract characteristic variables with limited practical value; on the other hand, although there is a wealth of duality research, it is less involved in duality behavior at the entrepreneurial level, which has led to a lack of understanding of the behavioral modeling and leadership that occur at the top leadership level [8]. Thus, given that entrepreneurial improvisation generally occurs during the daily entrepreneurial behavior of entrepreneurs/teams [2], this paper raises a new research question of interest-what are the daily behavior patterns of entrepreneurs that may trigger dualistic improvisational behavior in themselves, their teams, and their organizations?

This question aims to uncover the microreasons behind the occurrence of two kinds of improvisation, i.e., the daily trigger behaviors of entrepreneurs. The theoretical basis for such a hypothesis is the paradoxical theory of individual duality. This theory suggests that the executive is the dominant mechanism driving organizational duality and that this mechanism stems from the executive's deep perception of what is paradoxical, which gives him/her the ability to take subsequent actions to differentiate and integrate processing. Thus, this study proposes that entrepreneurs are able to handle the duality paradox properly and trigger exploratory and exploitative improvisational behaviors in themselves, their teams, and their organizations in a balanced manner through a series of daily entrepreneurial behaviors.

To address the above questions, it is important to followup by delving into the microlevel of entrepreneurial behavior. Drawing on the sociological design of ecological transient assessment, this study conducts structured observation and immediate recording of creators in the exploitative stage of entrepreneurship, so as to generalize the daily behavioral patterns of creators that trigger dual improvisation. This study not only contributes to an in-depth understanding of the occurrence and action logic of exploratory and exploitative improvisation in entrepreneurial practice, but also provides action plans for entrepreneurs at the operational level.

In order to make up for the shortcomings of the current research, we must go deep into the microlevel of entrepreneur behavior to track and investigate. The research objectives of this paper are as follows: (1) an entrepreneurs' improvisational behavior trigger pattern is constructed based on entrepreneurs' daily behavior research. This research draws on the ecological instant evaluation design of sociology and conducts structured observation and real-time recording of creators in the entrepreneurial development period, so as to conclude that creators trigger double metaimprovisational daily behavior pattern. (2) The influence of the trigger mode of improvisational behavior is evaluated. The highlights of this study are as follows: (1) the findings of this paper help to deeply understand the occurrence and action logic of exploratory and exploitative improvisation in entrepreneurial practice. (2) The findings of this paper provide entrepreneurs with action plans at an operational level.

\section{Materials and Methods}

2.1. Methodology of Duality Improvisation. In management, duality is a product of an organization's response to an increasingly fluid environment and is generally used to describe the level at which an organization handles seemingly contradictory matters, i.e., a balance between exploration and development. Exploration covers behaviors such as search, creation, change, and experimentation, while development covers behaviors such as condensation, improvement, efficiency, and implementation [9]. Most current research focuses on the above-team level, mostly adopting a time-separated view of how duality is balanced. Gupta et al. [10] argue that the higher the individual level, the more difficult it is to achieve the duality of the same unit and synchronization, because the unit has limited cognitive resources but often needs to switch affairs, and it is difficult to adjust its thinking in time in complex work. In recent years, the thought of paradox theory school has challenged these views [11]. Smith and Tushman [12] suggest that business executives may use paradoxical thinking to perceive contradictory matters and then take subsequent actions to differentiate and integrate processing to influence their own and organizational duality; Papachroni et al. [13] argue that individuals should view exploration and exploitation as inseparable parts of the same task rather than two contradictory tasks, and then use paradoxical thinking to integrate action. Several empirical studies have also shown that specific individual background, cognitive, and skill characteristics enhance individual duality, including a harmonic equilibrium for simultaneous enhancement and a cyclical equilibrium for sequential enhancement [14-16]. All of the above examples imply that individuals are capable of engaging in a range of practical behaviors that enhance their duality. Existing trait and ability research is generally abstract and fragmented, lacking practical operationalization, and does not provide a clear understanding of how individual duality behaviors are triggered at the explicit behavioral level.

Scholars' exploration of dual entrepreneurial improvisation has helped to clarify the duality, initiative, dimensions of occurrence, and causes of entrepreneurial improvisation, laying the theoretical foundation for subsequent qualitative research to be conducted. Regarding the duality of entrepreneurial improvisation, scholars have pointed out that entrepreneurial improvisation is the action process of spontaneously and creatively piecing together the resources at hand to solve immediate entrepreneurial problems, when 
conception and execution are almost simultaneous [17]. Many early scholars have equated improvisation with exploratory-type activities [18]. Some scholars propose that planning and improvisation are two ends of a continuum. However, improvisation may in fact be a transient plan that is made and then quickly executed; its action content is not necessarily new and may be an improvement on the original plan [17]. It is evident that improvisation should also include exploitative features. Cunha et al. [3] have realized at an early stage that although improvisation appears to have a transient abrupt change effect on the organization, its essence is still a long-term gradual change effect, and they suggest that entrepreneurial improvisation helps to address the two entrepreneurial challenges of stability and change simultaneously. Afterward, Hadida and Tarvainen [2] also pointed out that some firms one-sidedly view improvisation as an exploratory activity, leading them to fall into the innovation failure trap, which is an important reason why empirical studies have found a double-edged sword effect of improvisation-a dual imbalance of exploration and exploitation [9]. In their paper, they also explicitly mention improvisation as "a form of organizational exploration and development change process," which includes both random exploration and creation as well as basic additions and updates [5]. The latest case study of Du et al. [19] revealed the dual nature of improvisation and found that the effective improvisational innovation process of the science and technology innovation team is an organic switching process between improvised search and improvised construction. Several other empirical studies have also found that entrepreneurial improvisation has the dual utility of increasing flexibility and reducing risk and has a positive impact on dual innovation $[19,20]$. The above studies solidly establish the theoretical basis for exploratory and exploitative improvisation and reflect the ability of entrepreneurial firms to actively trade off choices and purposefully improvise to face transient opportunities and challenges. However, what the behavioral basis is for these improvisations to occur has not yet been discussed. Moreover, most of the studies are based on questionnaires, recall interviews, etc., which have their own limitations to observe entrepreneurs' improvisational behavior trigger patterns.

Previous mainstream research has viewed improvisation as a reactive mode of behavior that responds to unexpected changes in the environment, based on the assumption that entrepreneurial improvisation is the use of resources at hand to respond quickly to unexpected events and "learning by doing" behavior [21]. Baker et al. [22] argue that as the risk of entrepreneurial activity increases, unexpected opportunities arise frequently, and the effectiveness of the original plan becomes less and less effective, requiring sufficient improvisational skills at the decision-making level to respond [23]. The effect logic of "learning by doing" is the key business rule for entrepreneurs in the era of sudden change. However, we should not overlook the fact that the effect logic also implies another layer, which is "to start from analyzing the existing means, to act actively to create or discover opportunities, and finally to obtain satisfactory results" [24]. This logic clearly includes the proactive decision-making mode of the entrepreneur. Today's entrepreneurial improvisation is not just an ad hoc, reactive response by companies.

Hadida and Tarvainen [2] have pointed out that improvisation may occur at any level of the organization, including individuals, teams, and the entire organization, and implies the same behavioral logic. Shane and Venkataraman [25] also point out earlier that entrepreneurial behavior of entrepreneurs is the integration of a series of exploratory and exploitative activities that require a balanced disposition. Exploratory and exploitative improvisation may also produce synchronous harmonic equilibrium or sequential cyclical equilibrium, and interactive gain effects emerge [9]. For example, an entrepreneur's improvisational exploration may lead to subsequent individual and organization-wide improvisational development, and piecing together the creative resources in one improvisational development may induce new improvisational explorations. Of course, the improvisation and development that occur in entrepreneurial practice may be more complex and may appear to be either sequential or multifaceted. According to Farjoun [26], entrepreneurs are expected to do some exploratory work in any routine work, and there is inevitably a need to follow certain norms in any innovative work.

Duality improvisation is the balanced play of exploratory and exploitative improvisation over a period of time [2], and improvisational behaviors generally occur randomly in daily entrepreneurial activities. Tushman et al. [27] propose that CEOs need to possess three action qualities to maintain the balance of exploratory and exploitative activities in the firm: (i) developing and implementing forward-looking strategies, (ii) maintaining a balance between the needs of the innovation and base units, and (iii) tolerating conflict. Contextual duality theory has also stated that executives with duality exhibit four qualities: innovative thinking, reciprocal beliefs, good liaison, and versatility [28]. All these studies corroborate the idea that the qualities and skills of individuals are important antecedents to enhance their duality. However, both cognitive and skills are relatively abstract individual characteristics that may be inconvenient for firms to operationalize when developing and applying these competency qualities. Placing entrepreneurial improvisation in context, the study shows that factors such as harmonious passion, inclusive leadership, resource pooling, experimental culture, and risk taking in entrepreneurial teams can influence the level of (dual) entrepreneurial improvisation.

To this end, this study will extract a large number of entrepreneurs' daily behaviors through an observational method and code and categorize them into several entrepreneurial behavior patterns, through which the daily behavior patterns behind the generation of bimodal improvisational behaviors will be revealed.

2.2. Observation Method. This study draws on the design ideas of the ecological momentary assessment (EMA) method of sociological research to capture the occurrence of dual entrepreneurial improvisational behaviors and the trigger patterns behind them [29]. The ecological momentary assessment method is a method that allows respondents 
to report their behaviors and experiences multiple times in a real-time environment [30]. This method provides timely feedback on transient behaviors occurring in a specific setting, tracks changes in behaviors as they occur, and is effective in avoiding recall errors, subjective biases, etc. of the respondents, which is well suited for studying spontaneous behaviors such as improvisation and establishing the ecological validity of entrepreneurial behavior research. A combination of structured observation and interview method was adopted to remedy the abovementioned shortcomings. This method has the usual high openness and flexibility of the observation method but also sets up structured data processing and survey instruments that are most suitable for in-depth study of human behavior [31]. Placed in the context of this study, this method allows for more accurate identification of various categories of entrepreneurial behavior categories, which can then be used to form specific behavior patterns by recording, coding, and categorizing them in a timely manner.

2.3. Sample Selection. In order to take into account the characteristics of the keywords "entrepreneur" and "dual improvisation," this study considers Chinese creators as the most representative sample. First, creators were originally defined as "people who are brave enough to innovate and try to turn their ideas into reality," so it is clear that Chinese creators are innovation-oriented entrepreneurs. Second, creators' teams are generally small in size and scarce in material resources, so they often cannot clearly separate exploration and development activities, and most strategic decisions are made by the creators themselves (founders). Third, creators mainly rely on their knowledge and innovation skills in exchange for capital and market returns, and innovation is the basis of their business, which fits well with the applicable context and measurement content of dual improvisation [9]. Therefore, the daily behavior of creators is more relevant to the purpose of this study than that of entrepreneurs in general. The researcher made initial contact with 19 Chinese creators who had achieved pre-entrepreneurial success, explained the purpose and methodology of the survey, and sought their consent. According to Eisenhardt [32], these 19 entrepreneurs met the sampling criteria of the structured observation method.

2.4. Data Collection. The research team conducted structured observations and interviews with these 19 creators throughout the period from January to May 2021, with a total of 304 hours. Since improvisation generally occurs in the course of the creator's daily behavior without notice, the researcher had to follow the creator throughout the agreed open hours, including observing his/her/their body language and emotional changes, in order to capture on the spot all the improvised behaviors occurring in the creator himself/herself and his/her team and organization. This is supplemented by occasional questioning to confirm any concerns. We confirmed with the creator to ensure the randomness and representativeness of the survey [33]. Based on the previous definition of the concept of entrepreneurial improvisation, the researcher identified all entrepreneurial improvisation behaviors of the creators and recorded the activities they engaged in when they occurred [17], including the behaviors of the creators that triggered improvisation of their core team and employees on the spot, recording the behaviors at each improvisation. Since this study only explores the impact of creators' individual behaviors on their own and organizational improvisation behaviors, only the on-the-spot improvisation behaviors of teams and employees induced by creators are tracked and observed, and other unobserved scenarios cannot be covered.

2.5. Analysis Method: Grounded Theory. Since the grounded theory was proposed [34], scholars have made some modifications to the practical steps and requirements of the method. In this paper, we summarize the general research path of grounded theory based on the current research of grounded theory method. Grounded theory research consists of three main steps. First is data collection. The data here refers to broad data, including secondary information such as academic research literature, cases, government regulations and policy documents, and also primary information obtained through field research such as in-depth interviews and questionnaires. Next is the data analysis session. The data analysis session includes open decoding (coding), spindle (axial) decoding (coding), and selective decoding (coding). Open decoding must discard any presuppositions and decompose, examine, compare, conceptualize, and analogize the data. Spindle decoding is the formation of class genera based on open decoding and the examination of the relationships between the classes. The paradigm model of decoding in this stage can be linked according to the development sequence. The development sequence of the paradigm model of decoding is "cause-effect-phenomenon-context-mediated condition-action strategy-result." Selective decoding is the distinction between core and support genera in the class genus. Finally, there is theory construction, which integrates various theoretical elements through a story line.

2.6. Evaluation Method: Pairwise Hesitation Fuzzy Set. In order to integrate the evaluation information of decision creators from multiple perspectives, Atanassov [35, 36] has first proposed the concept of intuitionistic fuzzy sets based on fuzzy sets. In order to describe and collect uncertain evaluation information of decision creators more precisely, Torra [37] proposed the concept of hesitant fuzzy sets. Intuitionistic fuzzy sets contain both affiliation and nonaffiliation degrees but do not involve the decision maker's hesitation degrees in affiliation and nonaffiliation degrees. In contrast, the hesitant fuzzy set can effectively express the decision maker's hesitation degree but does not involve the nonaffiliation degree. Therefore, combining the characteristics of intuitionistic fuzzy sets and hesitation fuzzy sets, Zhu et al. [38, 39] have proposed the concept of pairwise hesitation fuzzy sets as follows. 
Let $X$ be a finite nonempty set; then, the set $D$ is said to be a pairwise hesitant fuzzy set, which can be expressed as [38]

$$
D=\{\langle x, h(x), g(x)\rangle \mid x \in X\},
$$

where $h(x)$ and $g(x)$ denote the subordination and nonsubordination of element $x$ to the set $D$, respectively. $h(x)=\left\{\gamma_{1}, \gamma_{2}, \ldots, \gamma_{\# h(x)}\right\}, g(x)=\left\{\eta_{1}, \eta_{2}, \ldots, \eta_{\# g(x)}\right\}, \gamma_{i} \in$ $[0,1], i=1,2, \ldots, \# h(x), \quad \eta_{j} \in(0,1), j=1,2, \ldots, \# g(x)$, and $\# h(x)$ and $\# g(x)$ denote the number of elements in the affiliation and nonaffiliation degrees, respectively. The affiliation and nonaffiliation degrees should satisfy the condition $\gamma^{*}+\eta^{*} \leq 1$, where $\gamma^{*}$ and $\eta^{*}$ denote the maximum of the affiliation and nonaffiliation degrees, respectively.

For ease of understanding and calculation, according to equation (1) [38], $d(x)=\langle h(x), g(x)\rangle$ is called pairwise hesitant fuzzy element and can be abbreviated as $d=\langle h, g\rangle$. Zhu et al. [38] proposed the score function, exact function, and comparison method of paired hesitant fuzzy elements, so as to facilitate the comparison of paired hesitant fuzzy information.

Let $d=\langle h, g\rangle$ be an arbitrary pairwise hesitant fuzzy element, $h(x)=\left\{\gamma_{1}, \gamma_{2}, \ldots, \gamma_{\# h(x)}\right\}, \quad g(x)=\left\{\eta_{1}, \eta_{2}, \ldots\right.$, $\left.\eta_{\# g(x)}\right\}$, and $\# h(x)$ and $\# g(x)$ denote the number of elements in the affiliation and nonaffiliation degrees, respectively.

Then, the score function for this pair of hesitant fuzzy elements is

$$
s(d)=\frac{1}{\# h} \sum_{i=1}^{\# h} \gamma_{i}-\frac{1}{\# g} \sum_{i=1}^{\# g} \eta_{i} .
$$

The exact function is

$$
\rho(d)=\frac{1}{\# h} \sum_{i=1}^{\# h} \gamma_{i}+\frac{1}{\# g} \sum_{i=1}^{\# g} \eta_{i} .
$$

Based on the score function and the exact function, two arbitrary pairwise hesitant fuzzy elements $d_{1}$ and $d_{2}$ are compared.

If $s\left(d_{1}\right)>s\left(d_{2}\right)$, then $d_{1}$ is considered better than $d_{2}$, which can be expressed as $d_{1} f d_{2}$

If $s\left(d_{1}\right)<s\left(d_{2}\right)$, then $d_{1}$ is considered not superior nor inferior to $d_{2}$, which can be expressed as $d_{1} p d_{2}$

If $s\left(d_{1}\right)=s\left(d_{2}\right)$, then we need to continue to consider the exact function value

If $\rho\left(d_{1}\right)>\rho\left(d_{2}\right)$, then $d_{1}$ is considered better than $d_{2}$, which can be expressed as $d_{1} f d_{2}$

If $\rho\left(d_{1}\right)<\rho\left(d_{2}\right)$, then $d_{1}$ is considered not superior nor inferior to $d_{2}$, which can be expressed as $d_{1} p d_{2}$

If $\rho\left(d_{1}\right)=\rho\left(d_{2}\right)$, then $d_{1}$ and $d_{2}$ are considered to be nondifferentiable and can be expressed as $d_{1}: d_{2}$

Based on the comparison method of pairwise hesitant fuzzy elements, the simplest method of ranking pairwise hesitant fuzzy sets can be obtained.

First, define a priority value for any two pairwise hesitant fuzzy elements $d_{1}$ and $d_{2}$.

$$
p v\left(d_{1}, d_{2}\right)= \begin{cases}1, & \text { if } d_{1} f d_{2}, \\ 0, & \text { if } d_{1}: d_{2}, \\ -1, & \text { if } d_{1} p d_{2} .\end{cases}
$$

Let $D_{1}=\left\{d_{11}, d_{12}, \ldots, d_{1 m}\right\}$ and $D_{2}=\left\{d_{21}, d_{22}, \ldots, d_{2 m}\right\}$ be two hesitant fuzzy sets with the same number of dyadic hesitant fuzzy elements. Calculate the combined priority values of $D_{1}$ and $D_{2}$ :

$$
\operatorname{spv}\left(D_{1}, D_{2}\right)=\frac{1}{m} \sum_{i=1}^{m} p v\left(d_{1 i}, d_{2 i}\right) \text {. }
$$

Then, the comparison of $D_{1}$ and $D_{2}$ is as follows:

If $\operatorname{spv}\left(D_{1}, D_{2}\right)>0$, then $D_{1}$ is better than $D_{2}$, abbreviated as $D_{1} f D_{2}$

If $\operatorname{spv}\left(D_{1}, D_{2}\right)<0$, then $D_{1}$ is not better than or worse than $D_{2}$, abbreviated as $D_{1} p D_{2}$

If $\operatorname{spv}\left(D_{1}, D_{2}\right)=0$, then $D_{1}$ and $D_{2}$ are indistinguishable, abbreviated as $D_{1}: D_{2}$

2.7. Empirical Results. In this paper, the data provided by observation data and interview data were openly decoded. Various literature materials were read repeatedly and carefully for conceptualization and abstraction. The concepts were refined by constant comparison, and the categories were divided. Initially, the code was broad and then gradually narrowed until the number was saturated. We open-ended decode the data around the theme of "creator behavior pattern." The levels of open decoding are set according to the logical relationships. A total of 39 concepts were extracted from the primary and secondary codes. The concepts are grouped into their respective phenomena to form 6 categories (creator behavior patterns), as shown in Table 1. In this study, six creator behavior patterns that trigger dual improvisation of creators themselves, their teams, and their organizations are distilled. Briefly, these behavioral patterns involve key words such as building internal and external network relationships, conducting unplanned actions, nurturing an experimental atmosphere, stimulating ambivalent thinking, leading demonstrations, and guiding ambiguous decisions, in which creators are prone to stimulate binary improvisation behaviors in themselves, their teams, and the organization's employees when engaging in these activities.

As shown in Table 1, we can get the following six trigger patterns.

2.7.1. External Relationship Type. Researchers have found that creators generally lead a great deal of outreach work with including innovation partners, customers, experts, and even competitors. Between repeated communication and interactions, much exploratory and exploitative improvisation can be generated. Furthermore, it is evident that creators are consciously drawing on this influx of external information to induce their own improvisation. For example, in order to gain inspiration for a new model of 
TABLE 1: Six behavioral patterns that trigger bimodal improvisation.

\begin{tabular}{|c|c|c|}
\hline Mode & Main category & Conceptualization \\
\hline 1 & $\begin{array}{c}\text { External relationship } \\
\text { type }\end{array}$ & $\begin{array}{c}\text { A1: cooperative enterprises } \\
\text { A2: collaborative innovation } \\
\text { A3: partnerships } \\
\text { A4: conferences and forums } \\
\text { A5: school-enterprise exchanges } \\
\text { A6: customer engagement }\end{array}$ \\
\hline & & $\begin{array}{l}\text { A7: cooperative research } \\
\text { institutions }\end{array}$ \\
\hline 2 & $\begin{array}{l}\text { Internal relationship } \\
\text { type }\end{array}$ & $\begin{array}{c}\text { A8: team members } \\
\text { A9: individual resources } \\
\text { A10: team knowledge } \\
\text { heterogeneity } \\
\text { A11: team relationship training } \\
\text { A12: informal communication } \\
\text { A13: reduced power distance } \\
\text { A14: autonomous decision } \\
\text { making } \\
\text { A15: improvisation }\end{array}$ \\
\hline
\end{tabular}

A16: division of labor A17: setting aside time

A18: informal activities

A19: resource reorganization and piecing together A20: forward thinking

$3 \quad$ Flexible time type

A21: identifying opportunities for innovation

A22: identifying threats of mutation

A23: literature reading

A24: information platform A25: program seminar

$4 \quad \begin{aligned} & \text { Improvised platform } \\ & \text { type }\end{aligned}$

A26: organizational climate building

A27: platform incentive mechanism
Typical activities

(1) Collaborative innovation with partner companies

(2) Consciously establish innovative partnerships, collide with each other in the communication process, and create and improve partnerships

(3) Inviting customers to participate in the whole process of research, development, and sales and deal with unexpected problems together (4) Organizing and participating in conferences and forums for entrepreneurs in the industry

(5) Participating in school-enterprise exchanges organized by higher education institutions to gain inspiration for improvised exploration and development from teachers and students

(6) Establishing long-term partnerships with research institutions

(1) Leveraging team members' personal resources to expand new business

(2) Creating and maintaining a high degree of team knowledge heterogeneity to stimulate the collision of ideas

(3) Team relationship training to enhance team members' sense of understanding, willingness to communicate, and common responsiveness

(4) Adopting informal communication, humor, and expressions of trust to reduce power distance and increase team members' willingness to make autonomous decisions and to improvise

(1) Dividing labor in the team for exploration and development and encouraging members to improvise

(2) Setting aside time for informal activities to explore fresh

information and ideas and refine programs

(3) Thinking about how to reorganize the existing resources of the company and boldly experiment with them

(4) Frequent market monitoring and forward thinking for executives themselves

(5) Setting aside "unhindered time" to think about current opportunities for innovation or threats of sudden change without being disturbed by employees and customers

(6) Reading literature published by leading scholars and entrepreneurs and putting useful insights into practice immediately

(1) Organizing regular cross-regional departmental video conferences to discuss ongoing projects and new ideas and welcoming unplanned proposals

(2) Assembling the creative team immediately to focus on response options and completely new solutions based on situational needs

(3) Creating an organizational atmosphere of trial and error and giving employees a relatively relaxed working environment

(4) Holding one-on-one informal meetings with middle and senior staff to randomly generate new strategic ideas

(5) Conducting an incentive mechanism for employees to propose feasible and innovative ideas, with criticism treated without malice

A28: new program

A29: guided impromptu discussion

A30: regular seminar meeting

(1) Encouraging employees and partners to come up with new solutions and, once implemented, closely monitoring these projects for any unforeseen situations that occur in the early stages and keeping track of them

(2) Frequently shifting exploration and development-related topics during regular meetings, leading impromptu discussions

(3) Holding regular meetings of teams at all levels to organize brainstorming and instant reflection

(4) Letting employees participate in the whole process when expanding new markets and opening subsidiaries, and providing framework guidance while boldly delegating execution

(5) Allowing the team to have different interpretations of the current ambiguous situation and reducing ambiguity in "learning by doing" 
TABLE 1: Continued.

\begin{tabular}{|c|c|c|c|}
\hline Mode & Main category & Conceptualization & Typical activities \\
\hline 6 & $\begin{array}{l}\text { Demonstration and } \\
\text { guidance type }\end{array}$ & $\begin{array}{l}\text { A33: challenging the status quo } \\
\text { A34: new approaches } \\
\text { A35: new ideas } \\
\text { A36: open behavior } \\
\text { A37: closed behavior } \\
\text { A38: organizational climate shift }\end{array}$ & $\begin{array}{l}\text { (1) Emphasizing "bold innovation" when identifying new market } \\
\text { opportunities and encouraging employees to generate new ideas, } \\
\text { challenge the status quo, and create new approaches } \\
\text { (2) Emphasizing "task orientation" when dealing with unexpected } \\
\text { situations, guiding employees to quickly improve programs, closing } \\
\text { loopholes, and solving problems in a timely manner } \\
\text { (3) Using more open behaviors in the early stages of innovation } \\
\text { projects and more closed behaviors in the mature stages overall } \\
\text { (4) Variably creating a relaxed or demanding team innovation climate } \\
\text { and switching between them in time } \\
\text { (5) Taking the lead in modeling exploratory and exploitative } \\
\text { improvisational behavior }\end{array}$ \\
\hline
\end{tabular}

human-computer dialogue, the creators lead their core team to attend a school-enterprise exchange organized by a university research institution, which has triggered a lot of improvisational exploration on the spot; the creators have established a long-term partnership with a university and served as the deputy director of the relevant research institution, which has allowed them to obtain a lot of cutting-edge information that would be used to trigger dual improvisation. These findings are further corroborated by existing literature perspectives. Individual-level studies such as Baker [22] and Evers and Gorman [40] point to the social capital of individual entrepreneurs (e.g., partners, customers, family, and friends) as an important source of rapid access to external knowledge and shaping the ability to piece together resources to enhance improvisation; organizational-level studies such as Witell [41] suggest that organizations can gain faster external resource access through existing network relationships, thereby triggering improvisational behavior. In contrast, this paper reveals more specifically that entrepreneurs adopt six behaviors to structure specific external network relationships to trigger two types of improvisational behaviors in a balanced manner.

2.7.2. Internal Relationship Type. Compared with the external relationship, the internal communication of the creator team is more frequent and close, and the degree of mutual investment is also greater, which is prone to strong network relationships [42]. In this regard, four types of conscious balancing behaviors are proposed. For example, to avoid the rigidity of thinking and knowledge closure brought by strong relationships, creators actively maintain a high degree of team knowledge heterogeneity to stimulate the collision of ideas; they often use informal communication to reduce the sense of power distance and enhance the members' willingness to improvise; and they also use the personal relationships of team members to expand business, which often leads to unexpected new ideas. Correspondingly, a recent study by Prashantham and Floyd [43] found that entrepreneurs use active team following to gain moral support, which in turn enhances the spontaneity of self-action. Specifically, on the one hand, entrepreneurs consciously build entrepreneurial teams with different domain knowledge, experience, and skills, aiming to assemble high-value, scarce, and hard-to- replicate competitive resources in time to cope with sudden changes; on the other hand, the shared work experience among members helps to enhance familiarity with each other and form shared team cognition to improve improvisational development efficiency. In addition, this study has further found that fostering entrepreneurial team relationships with medium-high heterogeneity, informal communication, and shared cognition can enhance the level of dual improvisation in a balanced manner.

2.7.3. Flexible Time Type. Entrepreneurs set aside unplanned working hours for active improvisation and development.

This section distills six ways to set aside time for unplanned work. The creator realizes the strategic importance of getting away from tedious daily tasks and exploring, reflecting, and refining strategic planning although he/she still spends most of his/her time doing planned work. As a result, almost every creator schedules dedicated time to plan for new markets, think about new opportunities, and absorb new knowledge. For example, the creator deliberately reduces his regular work time and focuses only on strategic matters and leading his team, which in turn leads him to a higher probability of improvisation. Another example is that the creator $\mathrm{H}$ spends a lot of time in the lab, delegating day-to-day tasks to his/her team and staff and working on his/her own to piece together the resources at hand to develop new opportunities and implement them boldly. In addition, all creators will do some division of labor in the team for exploration and development, encouraging team members to improvise.

Reviewing the connotation of improvisation, we find that although unplanned action itself is an integral dimension, improvisation units can still "engage in unplanned action in a planned manner" [17]. For example, Ciuchta [44], having viewed entrepreneurial improvisation in the $21 \mathrm{st}$ century from a strategic perspective, argued that firms should view the occurrence of improvisation strategically, rather than viewing it as sporadic and random actions. All of these theoretical perspectives suggest that entrepreneurs should incorporate "unplanned time" into their strategic planning and use it appropriately to trigger appropriate entrepreneurial improvisation in order to maintain organizational innovation. 
2.7.4. Improvised Platform Type. This paper finds that the creators have triggered exploratory and exploitative improvisational behaviors among employees by building tangible and intangible improvisation platforms (scenarios) in five ways, namely, cross-regional video conferences, ad hoc concentrations, trial-and-error atmosphere, informal conversations, and rewarding suggestions. For example, all creators organize ad hoc focused discussions based on situational needs; most creators are clearly creating a trial-anderror atmosphere to encourage employees to improvise; informal conversations with middle and senior management are often held, during which the openness and casualness encourage both parties to think boldly and reflect instantly, naturally triggering exploratory and exploitative improvisation; most creators have also established clear systems to reward employees for their suggestions, while not punishing or ignoring criticism. In general, the creators consciously create a harmonious passionate atmosphere in the organization, building an invisible platform for the team and employees to improvise and motivating them to improvise boldly and timely [6].

2.7.5. Stimulating Thinking Type. In the same way as building a platform, creators stimulate employees' divergent and convergent thinking by playing the role of professional mentors with five behaviors that also bring more dual improvisation. An et al. [45] also suggest that the complete innovative behavior is an integrated embodiment of divergent and convergent thinking. This study has found that the creators use specific mentor behaviors such as highly investing in the innovation process; encouraging divergence and then emphasizing aggregation; organizing brainstorming; and empowering and guiding employees to balance and coordinate their thinking focus, exercise their contradictory thinking skills, and allow them to be able to do their own work and to properly handle the balanced relationship between improvised exploration and improvised development. The last behavioral pattern that triggers dual improvisation is guided collective ambiguous decision making, with 2 behaviors attributed to it. First, the creator allows the team to have different interpretations of the current ambiguous situation, reducing ambiguity as they learn by doing. In this process, improvisational exploration and improvisational development are triggered successively. Second, all the creators emphasize that teams should look for "good enough solutions" rather than "perfect solutions" in emergent situations, which would speed up decision making and tension, thus triggering two types of improvisational behaviors.

Brun et al. [46] argue that ambiguity management plays an important role in innovation contexts. Although ambiguity limits the innovator's understanding of immediate opportunities or threats, constrains the level of resource allocation, and reduces the possibility of rational decision making, it precisely induces more improvisational behavior. Thus, there must be a greater tolerance for ambiguity in the idea generation phase or even intentionally created new ambiguities to stimulate improvisational exploration; however, in the solution selection phase, ambiguity tolerance must be reduced and improvisational development behaviors must be used to improve decision efficiency [47]. The results of this study validate exactly this idea.

2.7.6. Demonstration and Guidance Type. Various leadership behavior theories are emphasizing that the demonstration effect of leaders significantly affects employees' attitudes and behaviors [48]. Given that innovation is a dynamic process, not taking contextual changes into account would undoubtedly limit the practical relevance of the study. This study has found that almost all creators adopted dual leadership behaviors to guide members' dual improvisation. Dual leadership behaviors include leaders modeling open behaviors, which are behaviors that encourage and guide employees to explore new knowledge, challenge the status quo, and create new approaches, and closed behaviors, which encourage and guide employees to improve the status quo and accomplish task targets in a timely manner. In this study, creators generally used more open behaviors to induce exploratory improvisation in the early stages of innovation projects and closed behaviors to induce exploitative improvisation in the mature stages [48]. The analysis reveals that the creators often faced task situations that urgently required improvisation to be created at the beginning of the project and to be refined at the maturity stage, and the creators used power-change modeling behaviors to more accurately trigger employees' binary improvisation to respond to these situations.

In addition, all creators take the lead in experimenting with both improvisational behaviors and power shift to create a relaxed or harsh creative climate to trigger employee behavior. Admittedly, it is not easy to flexibly shift between exploration and exploitation, and creators can only lead more employees to gather the courage to proactively try dual improvisational behaviors if they take the lead, skillfully demonstrate improvisational exploration and exploitation skills, and establish a facilitative regulatory focus [23].

In addition, there are two other findings. First, because the structured observation method provides an overview of improvisational events, the researchers found that in complex daily entrepreneurial activities, exploratory and exploitative improvisation for different activities may occur simultaneously for creators, but the two types of improvisation in a single activity generally occur in an orderly manner. This not only corroborates the existence of improvisation duality, but also reveals the process logic of its occurrence, which is also consistent with findings of Du et al. [19]. Second, Harris et al. [49] have pointed out that entrepreneurs have the ability to choose and practice their behaviors and skills as self-determiners.

In order to evaluate and rank the influence of entrepreneurial models, this paper constructs a hesitant fuzzy set containing six pairwise hesitant fuzzy elements as $D=\left\{d_{1}, d_{2}, d_{3}, d_{4}, d_{5}, d_{6}\right\}$, where the six elements can be expressed as 


$$
\begin{aligned}
& d_{1}=\langle(0.1,0.2),(0.1,0.2)\rangle \\
& d_{2}=\langle(0.2,0.3),(0.1,0.2,0.3,0.4)\rangle \\
& d_{3}=\langle(0.4,0.5),(0.4,0.5)\rangle \\
& d_{4}=\langle(0.1,0.2,0.3,0.4),(0.2,0.3)\rangle \\
& d_{5}=\langle(0.3,0.4),(0.1,0.2)\rangle \\
& d_{6}=\langle(0.5,0.6),(0.3,0.4)\rangle .
\end{aligned}
$$

Using equation (5) and making $\theta=0.5$, we are able to obtain their new score function values as sn $\left(d_{1}\right)=-0.075$, sn $\left(d_{2}\right)=-0.115$, sn $\left(d_{3}\right)=-0.225$, sn $\left(d_{4}\right)=-0.135$, sn $\left(d_{5}\right)=$ 0.275 , sn $\left(d_{6}\right)=0.047$. They are ordered as

$$
d_{5}>d_{6}>d_{1}>d_{2}>d_{4}>d_{3} .
$$

\section{Results and Discussion}

Based on the paradoxical theoretical perspective of individual duality, this paper explores how entrepreneurs' daily behavioral patterns trigger dual improvisation behaviors in themselves, their teams, and their organizations. Six behavioral patterns that trigger duality improvisation have been extracted from the observed raw phenomenal data, containing 39 specific behaviors. This paper makes some theoretical and practical contributions to the study of bimodal entrepreneurial improvisation.

This paper contributes to the application of the duality concept in the field of entrepreneurial improvisation by identifying the occurrence of exploratory and exploitative improvisation behaviors and their equilibrium logic at the microindividual level. Although existing improvisation research has initially revealed the existence value and positive utility of duality, it is difficult for quantitative-based approaches to interpret when and how exploratory and exploitative improvisation occur and coexist in everyday entrepreneurial activities. This study has found that exploratory and exploitative improvisation may occur simultaneously in different activities within the same scenario, i.e., harmonic equilibrium, in complex entrepreneurial activities through the whole observation, which indicates that creators need to have the ability to continuously switch their way of thinking and behaving; however, the two kinds of improvisation occur mostly in an orderly manner in the same activity and obey the cycle equilibrium logic. The above findings echo Du et al.'s [29] study of improvisation processes and Tushman et al.'s [38] and Papachroni and Heracleous's [11] dual paradoxical theoretical perspectives. Moreover, the results show that creators engage in improvisation development almost twice as often as in improvisation exploration, which shows that dual improvisation is not mechanically maintaining a consistent amount of improvisation, but rather exerting it according to the local context. This is in line with Cunha et al.'s [3] idea of "mutation in gradual change" and Hadida and Tarvainen's [2] idea of "exploration in the long run of development," discussed earlier, and it is true that in practice, there are indeed many trivial matters that need to be developed and it is impossible for creators to get involved in new fields at will. This paper contributes to the study of the antecedents of binary improvisation by refining a model of creator behavior that has high operational value in triggering binary improvisation. While these variables advance our understanding of how entrepreneurial improvisation arises, a clear and complete picture of the action is always missing. This study observes all improvisational behaviors of entrepreneurs on a given day at the microlevel, which not only reveals more concretely the explicit behavioral underpinnings of improvisation occurrence, but is also more integrated than previous studies. The six behavioral models proposed in this paper not only corroborate previous research well, but also have more specific, explicit, and innovative findings [43]. On the other hand, although both exploratory and exploitative improvisation are triggered by seemingly separate behaviors, when the entire entrepreneurial process is viewed from a longitudinal perspective, all triggering behaviors coexist in a broader spatiotemporal context, and many of them belong to the same behavioral pattern. This reflects the need of entrepreneurs not only to improvise separately for different products, services, and processes, but also to flexibly shift their thinking and skills to trigger both improvisational behaviors at the lowest (cognitive) cost. This paper validates the paradoxical theoretical view of duality and finds that entrepreneurs have the ability to proactively coordinate and allocate resources to simultaneously engage in exploratory and exploitative improvisation and to take a series of actions to guide team and organizational members to do so together. Admittedly, it is difficult for resource-strapped and organically structured startups to segregate exploration and exploitation strictly through a division of labor, thus requiring a higher level of paradoxical cognitive ability from the entire staff; in particular, the leadership role of the entrepreneurs themselves should not be taken lightly. Although the dual context school proposes that members of the same unit can each handle the balance of exploration and development, it is difficult to sublimate individual dual equilibrium into organizational dual equilibrium without the orderly guidance and global control of superiors [17]. Thus, this paper highlights the leading role of entrepreneurial leaders in the dual improvisational behavior.

The policy implications from the results of this paper are as follows: (1) Different organizations and teams should fully consider the entrepreneurial improvisation behavior pattern of entrepreneurs when formulating entrepreneurship and innovation policies. (2) The formulation of different policies should be conducive to stimulating the improvisation of entrepreneurs. (3) The policy-making team needs to fully face and pay attention to the fact that different entrepreneurial improvisation behavior patterns have different effects on entrepreneurial activities.

\section{Conclusions}

This study provides a guide for entrepreneurs to successfully adopt a specific set of behavior patterns to trigger dual entrepreneurial improvisation and thus enhance 
entrepreneurial innovation performance. The context and environment in which most entrepreneurs operate dictates that they must organize tasks autonomously, either strategically or unconsciously, and they deal with dual paradoxes on a daily basis [26]. This study has also found that a large number of instantaneous changes and brainstorms occur in daily entrepreneurial activities, and creators need to play different roles when triggering different improvisations. For example, when triggering exploratory improvisation behaviors, creators often play the role of explorers and designers, proactively exploring uncharted territories and constructing future strategies. When triggering exploitative improvisation behaviors, creators play the role of scavengers, focusing on the precise execution of a task and solving various practical problems. Most importantly, creators need to be adept at adapting quickly in these roles in order to improve their dual improvisation skills in a balanced manner. The six entrepreneurial behavior patterns proposed in this study can be summarized as "building internal and external networks, conducting unplanned actions, nurturing an experimental climate, stimulating ambivalent thinking, leading by example, and guiding ambiguous decisions." Therefore, entrepreneurs should try to operate these behaviors, such as proactively building moderately strong and highly heterogeneous social networks in their daily work, setting aside unplanned time, encouraging trial and error, adjusting their own open and closed behaviors at the right time, and allowing collective ambiguous decision making. Moreover, as advocated by Balachandra [50], entrepreneurial improvisation can be enhanced through specific training or education. With reference to the behavioral connotations of these six patterns, this paper proposes that entrepreneurs should practice their dual goal-oriented communication, time management, and self-reflection skills in order to more accurately identify exploratory and exploitative attributes and timing and to reduce the risk of selfreinforcement; at the same time, they should be able to lead their employees variably and prioritize exploratory or exploitative matters according to the context in order to generate a wider range of model leadership.

Although this study has some useful findings, there are still some deficiencies: (1) The sample size needs to be expanded. (2) The research method of this paper is relatively single, which makes it difficult to overcome the limitations of the method. (3) The research cycle of this paper is short, and more abundant observation data can be obtained in a longer research cycle. (4) The research samples in this paper do not fully consider the gender differences of the research objects, which is also a field worthy of discussion. The research prospects of this paper are as follows: (1) The sample size of the research can be expanded, the research cycle prolonged, and more abundant observation data taken as the research samples. (2) A more comprehensive use of a variety of effective research methods is needed to overcome the limitations of a single method. (3) The gender differences of the research objects can be fully considered. (4) People's behavior trend and improvisation are also strongly affected by the architectural environment [51, 52]. The influence of architectural environment on behavior is an interesting and meaningful research field. This study does not involve the impact of work environment on entrepreneurs' entrepreneurial behavior. In future research, we can consider the impact of building environment factors on entrepreneurs' improvisation behavior.

\section{Data Availability}

The experimental data used to support the findings of this study are included within the article.

\section{Conflicts of Interest}

The authors declare that they have no conflicts of interest.

\section{Acknowledgments}

This work was supported by the Philosophy and Social Science Research Project for Universities of Jiangsu (Research on the Co-evolution of Innovation Ecosystem in the Era of Digital Economy in Jiangsu Province, project no. 2021SJA0485).

\section{References}

[1] C. Moorman and A. S. Miner, "The convergence of planning and execution: improvisation in new product development," Journal of Marketing, vol. 62, no. 3, pp. 1-20, 1998.

[2] A. L. Hadida, W. Tarvainen, and J. Rose, "Organizational improvisation: a consolidating review and framework," International Journal of Management Reviews, vol. 17, no. 4, pp. 437-459, 2015.

[3] J. V. D. Cunha and M. P. E. Cunha, "Organizational improvisation: change or stability?" Management Research: The Journal of the Iberoamerican Academy of Management, vol. 8, no. 2, pp. 81-100, 2010.

[4] Y. J. Lee, J. H. Lee, and K. S. Ham, "Balancing efficiency and flexibility in software project: the role of team collective improvisation, behavioral integration, and member diversity," Journal of Contemporary Eastern Asia, vol. 16, no. 1, pp. 22-48, 2017.

[5] M. P. Tempelaar and N. A. Rosenkranz, "Switching hats: the effect of role transition on individual ambidexterity," Journal of Management, vol. 45, no. 4, pp. 1517-1539, 2019.

[6] L. Xiong, "Improvise to win: the relationship between entrepreneurial improvisation and start-up competitive advantage," Asian Business \& Management, vol. 2020, 2020.

[7] P. Boumgarden, J. Nickerson, and T. R. Zenger, "Sailing into the wind: exploring the relationships among ambidexterity, vacillation, and organizational performance," Strategic Management Journal, vol. 33, no. 6, pp. 587-610, 2012.

[8] F. E. Klonek, T. Volery, and S. K. Parker, "Managing the paradox: individual ambidexterity, paradoxical leadership and multitasking in entrepreneurs across firm life cycle stages," International Small Business Journal: Researching Entrepreneurship, vol. 39, no. 1, pp. 40-63, 2020.

[9] A. K. Gupta, K. G. Smith, and C. E. Shalley, "The interplay between exploration and exploitation," Academy of Management Journal, vol. 49, no. 4, pp. 693-706, 2006.

[10] T. J. M. Mom, Y.-Y. Chang, M. Cholakova, and J. J. P. Jansen, "A multilevel integrated framework of firm hr practices, individual ambidexterity, and organizational ambidexterity," Journal of Management, vol. 45, no. 7, pp. 3009-3034, 2019. 
[11] A. Papachroni and L. Heracleous, "Ambidexterity as practice: individual ambidexterity through paradoxical practices," The Journal of Applied Behavioral Science, vol. 56, no. 2, pp. 143-165, 2020.

[12] W. K. Smith and M. L. Tushman, "Managing strategic contradictions: a top management model for managing innovation streams," Organization Science, vol. 16, no. 5, pp. 522-536, 2005.

[13] A. Papachroni, L. Heracleous, and S. Paroutis, "Organizational ambidexterity through the lens of paradox theory," The Journal of Applied Behavioral Science, vol. 51, no. 1, pp. 71-93, 2015.

[14] T. J. M. Mom, F. A. J. Van Den Bosch, and H. W. Volberda, "Understanding variation in managers' ambidexterity: investigating direct and interaction effects of formal structural and personal coordination mechanisms," Organization Science, vol. 20, no. 4, pp. 812-828, 2009.

[15] O.-P. Kauppila and M. P. Tempelaar, "The social-cognitive underpinnings of employees' ambidextrous behaviour and the supportive role of group managers' leadership," Journal of Management Studies, vol. 53, no. 6, pp. 1019-1044, 2016.

[16] T. Mu, A. van Riel, and R. Schouteten, "Individual ambidexterity in SMEs: towards a typology aligning the concept, antecedents and outcomes," Journal of Small Business Management, vol. 2020, pp. 1-32, 2020.

[17] D. Vera and M. Crossan, "Improvisation and innovative performance in teams," Organization Science, vol. 16, no. 3, pp. 203-224, 2005.

[18] S. Leybourne, "Project management and high-value superyacht projects: an improvisational and temporal perspective," Project Management Journal, vol. 41, no. 1, pp. 17-27, 2010.

[19] W. Du, J. Wu, S. Liu, and R. A. Hackney, "Effective organizational improvisation in information systems development: insights from the Tencent messaging system development," Information \& Management, vol. 56, no. 4, pp. 614-624, 2019.

[20] Y. Liu, D. Lv, Y. Ying, F. Arndt, and J. Wei, "Improvisation for innovation: the contingent role of resource and structural factors in explaining innovation capability," Technovation, vol. 74-75, pp. 32-41, 2018.

[21] K. M. Hmieleski, A. C. Corbett, and R. A. Baron, "Entrepreneurs' improvisational behavior and firm performance: a study of dispositional and environmental moderators," Strategic Entrepreneurship Journal, vol. 7, no. 2, pp. 138-150, 2013.

[22] T. Baker, A. S. Miner, and D. T. Eesley, "Improvising firms: bricolage, account giving and improvisational competencies in the founding process," Research Policy, vol. 32, no. 2, pp. 255-276, 2003.

[23] L. Hu, J. Gu, J. Wu, and A. A. Lado, "Regulatory focus, environmental turbulence, and entrepreneur improvisation," The International Entrepreneurship and Management Journal, vol. 14, no. 1, pp. 129-148, 2018.

[24] A. Mckelvie, G. N. Chandler, D. R. Detienne, and A. Johansson, "The measurement of effectuation: highlighting research tensions and opportunities for the future," Small Business Economics, vol. 4, pp. 323-342, 2019.

[25] S. Shane and S. Venkataraman, "The promise of entrepreneurship as a field of research," Academy of Management Review, vol. 25, no. 1, pp. 217-226, 2000.

[26] M. Farjoun, "Beyond dualism: stability and change as a duality," Academy of Management Review, vol. 35, no. 2, pp. 202-225, 2010.
[27] M. L. Tushman, W. K. Smith, and A. Binns, "The ambidextrous CEO," Harvard Business Review, vol. 89, no. 6, pp. 74-136, 2011.

[28] C. B. Gibson and J. Birkinshaw, "The antecedents, consequences, and mediating role of organizational ambidexterity," Academy of Management Journal, vol. 47, no. 2, pp. 209-226, 2004.

[29] A. A. Stone, J. E. Schwartz, J. M. Neale et al., "A comparison of coping assessed by ecological momentary assessment and retrospective recall," Journal of Personality and Social Psychology, vol. 74, no. 6, pp. 1670-80, 1998.

[30] M. A. Uy, M.-D. Foo, and H. Aguinis, "Using experience sampling methodology to advance entrepreneurship theory and research," Organizational Research Methods, vol. 13, no. 1, pp. 31-54, 2010.

[31] H. Mintzberg, "Structured observation as a method to study managerial work," Journal of Management Studies, vol. 7, no. 1, pp. 87-104, 1970.

[32] K. M. Eisenhardt, "Building theories from case study research," Academy of Management Review, vol. 14, no. 4, pp. 532-550, 1989.

[33] M. J. Martinko and W. L. Gardner, "Beyond structured observation: methodological issues and new directions," Managerial Work, vol. 10, no. 4, 2019.

[34] B. Glaser and A. Strauss, The Discovery of Grounded Theory; Strategies for Qualitative Research, Aldine Publishing Company, Chicago, IL, USA, 1967.

[35] Z. Hao, Z. Xu, H. Zhao, and Z. Su, "Probabilistic dual hesitant fuzzy set and its application in risk evaluation," KnowledgeBased Systems, vol. 127, pp. 16-28, 2017.

[36] K. T. Atanassov, "Intuitionistic fuzzy sets," Fuzzy Sets and Systems, vol. 20, no. 1, pp. 87-96, 1986.

[37] V. Torra, "Hesitant fuzzy sets," International Journal of Intelligent Systems, vol. 25, no. 6, pp. 529-539, 2010.

[38] B. Zhu, Z. Xu, and M. Xia, "Dual hesitant fuzzy sets," Journal of Applied Mathematics, vol. 2012, Article ID 879629, 13 pages, 2012.

[39] B. Zhu and Z. Xu, "Some results for dual hesitant fuzzy sets," Journal of Intelligent and Fuzzy Systems, vol. 26, no. 4, pp. 1657-1668, 2014.

[40] N. Evers and C. O'Gorman, "Improvised internationalization in new ventures: the role of prior knowledge and networks," Entrepreneurship \& Regional Development, vol. 23, no. 7-8, pp. 549-574, 2011.

[41] L. Witell, H. Gebauer, E. Jaakkola, W. Hammedi, L. Patricio, and H. Perks, "A bricolage perspective on service innovation," Journal of Business Research, vol. 79, pp. 290-298, 2017.

[42] S. Wei, Z. Chu, and W. Jingyi, "Internal social network, absorptive capacity and innovation: evidence from new ventures in China," Sustainability, vol. 10, no. 4, pp. 10941121, 2018.

[43] S. Prashantham and S. W. Floyd, "Navigating liminality in new venture internationalization," Journal of Business Venturing, vol. 34, no. 3, pp. 513-527, 2019.

[44] M. P. Ciuchta, J. O'Toole, and A. S. Miner, "The organizational improvisation landscape: taking stock and looking forward," Journal of Management, vol. 47, no. 1, pp. 288-316, 2020.

[45] D. An, Y. Song, and M. Carr, "A Comparison of two models of creativity: divergent thinking and creative expert performance," Personality and Individual Differences, vol. 90, pp. 78-84, 2016.

[46] E. Brun, A. Steinar Saetre, M. Gjelsvik, and M. Gjelsvik, "Classification of ambiguity in new product development 
projects," European Journal of Innovation Management, vol. 12, no. 1, pp. 62-85, 2009.

[47] T. J. Hwang and J. N. Choi, "Different moods lead to different creativity: mediating roles of ambiguity tolerance and team identification," Creativity Research Journal, vol. 32, no. 2, pp. 161-173, 2020.

[48] K. Rosing, M. Frese, and A. Bausch, "Explaining the heterogeneity of the leadership-innovation relationship: ambidextrous leadership," The Leadership Quarterly, vol. 22, no. 5, pp. 956-974, 2011.

[49] J. A. Harris, R. Saltstone, and M. Fraboni, "An evaluation of the job stress questionnaire with a sample of entrepreneurs," Journal of Business and Psychology, vol. 13, no. 3, pp. 447-455, 1999.

[50] L. Balachandra, "The improvisational entrepreneur: improvisation training in entrepreneurship education," Journal of Small Business Management, vol. 57, no. 1, pp. 60-77, 2019.

[51] C. Bedon and S. Mattei, "Facial expression-based experimental analysis of human reactions and psychological comfort on glass structures in buildings," Buildings, vol. 11, no. 5, 2021.

[52] C. Bedon and S. Mattei, "Remote facial expression and heart rate measurements to assess human reactions in glass structures," Advances in Civil Engineering, vol. 2021, Article ID 1978111, 16 pages, 2021. 